\title{
Impact of appropriate pharmaceutical therapy for chronic conditions on direct medical costs and workplace productivity: A review of the literature
}

\author{
Neil Goldfarb \\ Thomas Jefferson University \\ Christine Weston \\ Thomas Jefferson University \\ Christine W. Hartmann \\ Thomas Jefferson University \\ ABiltk@ Bikjirical additional works at: https://jdc.jefferson.edu/healthpolicyfaculty \\ J'omas Jefferson University \\ Part of the Health Services Research Commons \\ Alleit Gronkfordow how access to this document benefits you \\ Thomas Jefferson University
}

\section{Recommended Citation}

S8fdfarb, Hope; Howell, Jamie ; Maio, Vittorio; Clarke, Janice; Nuthulaganti, Bhaskar; and Cobb, Nicole, "Impact of appropriate pharmaceutical therapy for chronic conditions on direct medical costs and workplace productivity: A review of the literature" (2004). College of Population Health Faculty Papers. Paper 3.

https://jdc.jefferson.edu/healthpolicyfaculty/3

This Article is brought to you for free and open access by the Jefferson Digital Commons. The Jefferson Digital Commons is a service of Thomas Jefferson University's Center for Teaching and Learning (CTL). The Commons is a showcase for Jefferson books and journals, peer-reviewed scholarly publications, unique historical collections from the University archives, and teaching tools. The Jefferson Digital Commons allows researchers and interested readers anywhere in the world to learn about and keep up to date with Jefferson scholarship. This article has been accepted for inclusion in College of Population Health Faculty Papers by an authorized administrator of the Jefferson Digital Commons. For more information, please contact: JeffersonDigitalCommons@jefferson.edu. 


\section{Authors}

Neil Goldfarb, Christine Weston, Christine W. Hartmann, Mirko Sikirica, Albert Crawford, Hope He, Jamie Howell, Vittorio Maio, Janice Clarke, Bhaskar Nuthulaganti, and Nicole Cobb 


\title{
Impact of Appropriate Pharmaceutical Therapy for Chronic Conditions on Direct Medical Costs and Workplace Productivity: A Review of the Literature
}

\author{
NEIL GOLDFARB, B.A., CHRISTINE WESTON, Ph.D., M.S.Ed., CHRISTINE W. \\ HARTMANN, M.S.S., MIRKO SIKIRICA, Pharm.D., ALBERT CRAWFORD, Ph.D., M.B.A., \\ HOPE HE, M.A., M.P.A., JAMIE HOWELL, Pharm.D., M.S., VITTORIO MAIO, Pharm.D., \\ JANICE CLARKE, R.N., B.B.A., BHASKAR NUTHULAGANTI, M.B.A., \\ and NICOLE COBB, M.A.O.M.
}

\begin{abstract}
This paper presents the findings of a literature review investigating the economic impact of appropriate pharmaceutical therapy in treating four prevalent chronic conditions-asthma, diabetes, heart failure, and migraine. The goal of the review was to identify high-quality studies examining the extent to which appropriate pharmaceutical therapy impacts overall medical expenditure (direct costs) and workplace productivity (indirect costs). The working hypothesis in conducting the review was that the costs of pharmaceuticals for the selected chronic conditions are offset by savings in direct and indirect costs in other areas. The literature provides evidence that appropriate drug therapy improves the health status and quality of life of individuals with chronic illnesses while reducing costs associated with utilization of emergency room, inpatient, and other medical services. A growing body of evidence also suggests that workers whose chronic conditions are effectively controlled with medications are more productive. For employers, the evidence translates into potential direct and indirect cost savings. The findings also confirm the importance of pharmaceutical management as a cornerstone of disease management. (Disease Management 2004;7:61-75)
\end{abstract}

\section{INTRODUCTION}

$\mathbf{E}$ SCALATING HEALTH CARE COSTS are a significant concern for policy makers and for employers, who, in the United States, bear a significant share of the total spending burden. ${ }^{1}$ In response to this trend, employers have sought ways to limit their health expenditure risks, such as defined contribution plans, benefit reductions, increased out-of-pocket payments (deductibles and co-payments), reduced choices among plans and providers, and tiered benefit plans. The pharmacy budget has been espe- cially susceptible to these strategies. The potential impact of having a "silo mentality," in which pharmacy benefit management decisions are made without reference to the total spending picture, has not been well studied.

Chronic conditions represent a public health issue of magnitude. While some conditions affect individuals of all ages, the prevalence for many increases with age. With the average age in the United States climbing, the prevalence of chronic conditions is expected to increase rapidly over the coming decade.

Evidence-based treatment guidelines and 
disease management programs for many chronic conditions emphasize appropriate pharmacotherapy as the cornerstone to improving health outcomes and controlling costs. Numerous studies have shown that appropriate medications for chronic conditions reduce symptoms and prevent or delay the onset of complications, resulting in improved health-related quality of life and workplace productivity. $^{2}$ This paper reports on a review of the literature examining cost impact of appropriate pharmaceutical care for selected chronic conditions.

\section{OBJECTIVE}

The working hypothesis of this review was that the cost of providing health insurance coverage that includes pharmaceutical treatment for chronic conditions potentially could be offset by the cost savings associated with decreased medical costs and work loss. We conducted a review of the literature describing the impact of appropriate medication use on costs of care, from an employer perspective. Two main categories of costs-direct medical costs associated with health care service utilization, and indirect costs associated with losses to workplace productivity-were examined. While other costs may be associated to different degrees with the studied conditions, this review was limited to the two categories of cost of greatest interest to employers. Workplace productivity was defined to include both absenteeism-missed days from work due to illness-and presenteeism-reduced output or performance for employees who present for work despite illness.

\section{METHODS}

Four chronic conditions-asthma, migraine, diabetes, and heart failure-were selected for review, based on their prevalence, costs, and relevance to employers, as well as the use of appropriate pharmacotherapy as a cornerstone of the management of each disease. A literature search, using the MEDLINE database, covering the time period between 1993 and 2003, was conducted to identify published studies in the peer-reviewed literature examining the impact of appropriate pharmaceutical agents on health care utilization and workplace productivity. Each identified manuscript was reviewed and evaluated on the basis of the following: (1) study design and methods, (2) study population, (3) class and name of drug(s) studied, (4) type(s) of health care use studied, (5) types of workplace productivity studied, (6) impact of therapy on health care use and costs, and (7) impact of therapy on workplace productivity. Reference lists of key publications were reviewed to identify other relevant articles, which, in turn, were obtained and reviewed.

\section{RESULTS}

The results of the literature review for each of the four chronic conditions examined are presented, including overviews of the epidemiology of the conditions and associated costs and summaries of the evidence of the impact of pharmaceuticals on direct and indirect costs.

\section{Asthma}

Asthma is one of the most prominent public health issues in children and adults. ${ }^{3,4}$ In the United States, asthma affects approximately 15 million individuals ${ }^{3}$ and is the most common illness in children and adolescents. ${ }^{5}$ On an annual basis, 5,000 deaths, 500,000 hospitalizations, and 2 million emergency department (ED) visits are attributed to asthma. ${ }^{6-8}$ Furthermore, asthma has been estimated to cause 14 million school absence days and 14.5 million work absence days annually. ${ }^{6}$ Accordingly, health care costs are substantial and were estimated to be $\$ 12.7$ billion in 1998., 9 The average annual cost per patient has been estimated at $\$ 1,238$. $^{10}$

The majority of asthma-related costs (58\%) are related to direct medical care expenditures, of which $45 \%$ are associated with hospitalizations, outpatient hospital visits, and ED visits and $43 \%$ with prescription medications. ${ }^{9}$ However, indirect costs-which include non-medical economic losses such as days missed from work and school, caregivers' costs, premature 
retirement, and death-represent $42 \%$ of the total health care expenses for the disease. ${ }^{9}$

Pharmacological therapy, along with patient education, control of asthma triggers, and the monitoring of asthma severity with objective measures of lung function, plays a central role in the National Heart, Blood, and Lung Insti-

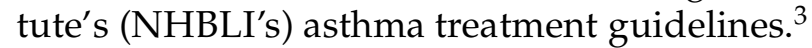
Despite these guidelines, the current use of controller medications is seriously suboptimal. ${ }^{11-13}$ Long-term-control medications, used to prevent and control disease symptoms while simultaneously reducing the frequency and severity of asthma, ${ }^{3}$ include inhaled and systemic corticosteroids, cromolyn sodium and nedocromil, long-acting beta2-agonists, methylxanthines, and leukotriene modifiers. Although inhaled corticosteroids are universally considered the most effective controllers and recommended as first-line therapy ${ }^{3,4}$ recent evidence from clinical trials indicates that the synergic association of beta2-agonists and corticosteroids might be beneficial for more effective long-term treatment, leading to improvements in lung function and symptoms, as well as a decreased need for rapid relief, short-acting medications. ${ }^{3,4,14}$ As a result, the 2002 updated NHBLI asthma guidelines recommend that the preferred treatment for patients with moderate to severe asthma be the addition of long-acting inhaled beta2-agonists to low-to-medium doses of corticosteroids. ${ }^{15}$

Impact of asthma drug therapy on health care utilization and direct costs. Several studies have documented an association between the increased use of inhaled corticosteroids among patients with asthma and a decrease in utilization of costly health care resources, namely, hospitalizations ${ }^{16-19}$ and ED visits. ${ }^{20}$ One large population-based study ${ }^{21}$ showed that the use of inhaled steroids was associated with a 50\% decrease in risk of hospitalization. A recent review $^{16}$ suggested that regular use of inhaled corticosteroids can decrease asthma hospitalizations by up to $80 \%$. A large retrospective study of acute hospitalization among 6 million people in Sweden between 1978 and $1991^{18}$ showed that increased sales of inhaled corticosteroids were significantly related to a downward trend in the total number of bed-days related to asthma.
Studies investigating the relative risk of return visits to the ED among users and nonusers of inhaled corticosteroids indicate that patients who use inhaled corticosteroids following discharge from the ED have a significantly lower risk of subsequent ED visits 22 and that inhaled corticosteroid therapy can reduce the risk of rehospitalization among elderly asthmatics. ${ }^{23}$ Perhaps most important is the finding that the regular use of inhaled corticosteroids is associated with a decrease in asthma mortality rates. $^{24,25}$

Studies consistently show that proper adherence to national asthma guidelines is associated with better clinical outcomes, lower health care utilization, ${ }^{11}$ and lower total health care costs, ${ }^{26}$ while poor adherence to therapeutic regimens is associated with excess health care utilization and costs. ${ }^{27,28} \mathrm{~A}$ study of adults with persistent asthma in France ${ }^{29}$ found that poorly controlled asthma was associated with a 2.5 -fold increase in utilization costs, compared with well-controlled asthma. Another study ${ }^{30}$ showed that the mean medication cost of patients whose medication use was at variance with treatment guidelines was double that of other asthma patients (\$89 vs. \$42), and the mean total health care cost of the non-guideline-compliant patients was almost three times that of other asthma patients (\$496 vs. $\$ 182$ ). A study in the Medicaid population ${ }^{26}$ found that patients being treated with corticosteroids had lower total health care costs (by $24 \%$ ) than patients without. These results are consistent with asthma cost-effectiveness models, which suggest that the use of inhaled corticosteroids in adults with mild to moderate asthma can decrease costs and improve quality of life. ${ }^{31}$

The impact of asthma on workplace productivity. A number of studies document the deleterious effects of asthma on quality of life and work productivity. ${ }^{32-38}$ Recent results from the 2000 Behavioral Risk Factor Surveillance System (using data from 163,773 respondents) indicate that adult asthmatics have significantly more physically unhealthy days, mentally unhealthy days, and days with activity limitation compared with adults without asthma. ${ }^{39}$

The impact of asthma on work-related im- 
pairment could be substantial. One populationbased study ${ }^{38}$ found that nearly a quarter of working asthmatics changed their job or duties because of their condition, another quarter reported missing at least one partial or complete work day in the last four weeks because of their asthma, and almost one-fifth rated their effectiveness on the job as less than or equal to $90 \%$ in the last four weeks. Similar findings were reported by Ungar and Coyte, ${ }^{32}$ who noted that most productivity loss among asthmatic patients results from restricted days rather than complete absenteeism. In light of the high rates of absenteeism to begin with, this additional cost to work productivity should be of special concern to employers.

Missed work and restricted days affect employees with asthma, as well as employees who have children with asthma. One study documented that among full-time working parents of children with asthma, 39\% of parents whose children awakened one to three times, and 69\% of parents whose children awakened four to seven times within a month's period, missed at least one day of work in that month. ${ }^{35}$ In an effort to estimate the patient-level costs of asthma care to children, Ungar and Coyte ${ }^{37}$ found that the indirect costs associated with parent productivity loss were $12 \%$ of the total health care costs, and almost half of the cost of medication, which accounted for $31 \%$ of the total. Given these facts, it is not surprising that, in one of the first studies to estimate the expense of asthma for a major U.S. employer, ${ }^{33}$ asthma wage-replacement costs due to absenteeism and disability (40\%) accounted for almost as much as those due to direct medical care (43\%).

Undertreatment of asthma can lead to higher direct medical costs as well as substantial indirect costs to employers, through absenteeism, impaired productivity and the ramifications of decreased quality of life among employees. ${ }^{40}$ Conversely, asthma patients with better asthma control have been shown to have lower health care costs, less work impairment, and a better quality of life. ${ }^{41}$ An increasing number of studies demonstrate that appropriate pharmacotherapy within the context of comprehensive asthma disease management programs can improve clinical outcomes, cost outcomes, and work productivity. ${ }^{42,43}$ Knoell et $\mathrm{al}^{44}$ demonstrated that patient adherence to medication guidelines led to improved work productivity. Similarly, outcomes of a population-based asthma management program showed an increase in quality of life, as well as a decrease in absenteeism for those who attended the program. ${ }^{45}$

The estimated cost savings to managed care organizations or employers who participate in asthma disease management programs can be substantial. For example, results from the Asthma Self-Management Program (ASMP) demonstrated that the estimated cost savings due to a reduction in the utilization of health care services were $\$ 175,317$. Since the cost of participating in the program was $\$ 49,500$, participating organizations yielded a net savings of $\$ 125,817$, or a return on investment of $254 \% .{ }^{46}$ One asthma intervention program, which trained providers to follow national asthma guidelines, estimated that the annual resource savings after the intervention amounted to $\$ 4,845$ per patient. ${ }^{47}$

\section{Diabetes}

In 2001, approximately 16.7 million adults in the United States were thought to have diabetes, and $7.9 \%$ of adults were diagnosed with the disease. ${ }^{48}$ The number of individuals with diabetes is expected to continue to increase, rising to almost 22 million by $2025 .{ }^{49}$ These individuals are at greater risk for neurological, peripheral vascular, cardiovascular, renal, and ophthalmic diseases than the non-diabetic population. ${ }^{50-53}$ In 2002 the total direct and indirect costs attributable to diabetes were estimated to be $\$ 132$ billion, averaging approximately $\$ 10,900$ per diabetic. ${ }^{50}$ This review focuses primarily on type 2 diabetes, which accounts for $90 \%$ or more of all cases of diabetes. ${ }^{54,55}$ Although type 2 diabetes is often asymptomatic in its early stages, as it progresses, it frequently results in serious long-term complications $^{56-58}$ and lower quality of life. ${ }^{59-61}$

The American Diabetes Association (ADA) treatment guidelines for type 2 diabetes focus on maintenance of glycemic control and screening for and attempting to prevent the onset or progression of complications. ${ }^{57}$ Other treatment approaches can include collaboration between health practitioners and patients, ${ }^{62,63}$ and disease management, which has been as- 
sociated with significant reductions in health care cost and use. ${ }^{64,65}$ While recommended treatment strategies for type 2 diabetes vary by individual case, at initial diagnosis they frequently include some combination of diet and exercise. ${ }^{57}$ As the disease progresses, for the majority of patients non-pharmacological interventions alone become insufficient to keep blood glucose levels within target ranges, often leading to the introduction of oral medications-alone, in combination, or together with insulin. ${ }^{66}$ However, patient compliance with treatment guidelines and preventive care standards has been shown to be less than optimal, especially in cases with more complicated treatment regimens. ${ }^{67-70}$ According to longitudinal study data, the number of patients who are able to maintain glycemic control using only one medication also decreases over time, and $50 \%$ in three years and $75 \%$ in nine years need multiple therapies to remain within acceptable levels. ${ }^{66}$ Medications to address complications are also frequently an important part of the treatment regimen. ${ }^{57}$

Impact of diabetes drug therapy on health care utilization and direct costs. Diabetes and its complications have substantial impacts on health care utilization..$^{50,71-79}$ According to 2002 data from the ADA, the estimated ratio of annual per capita medical expenditures for individuals with and without diabetes was approximately 5:1 ( $\$ 13,243$ vs. $\$ 2,560$, respectively). ${ }^{50}$ Previous studies support the findings that patients with type 2 diabetes have noticeably higher medical costs than similar patients without diabetes..$^{73,77}$

Brown et $\mathrm{a}^{74}$ assessed medical costs attributable to the progression of cardiovascular and renal disease in patients with type 2 diabetes and found that an individual's medical costs increased from baseline by $50 \%-360 \%$ for cardiovascular disease and by $65 \%-771 \%$ for renal disease, both depending on the stage of the disease. The authors emphasized the role of aggressive therapeutic treatments in lowering costs through a reduction in microvascular and marcovascular complications. Caro et $\mathrm{al}^{75}$ estimated the average direct costs of diabetes-related complications would amount to more than $\$ 47,000$ per person over 30 years of age. In their model, the major contributors to these costs included macrovascular diseases (52\% of total), nephropathy ( $21 \%$ ), neuropathy $(17 \%)$, and retinopathy $(10 \%) .{ }^{75}$ However, they noted that the ability to translate a reduction in the risk of complications into cost savings depends on the cost of the treatment involved.

The direct medical costs of diabetes are often determined by examining a variety of health care expenditures, including but not limited to hospitalization, medication, nursing home, and physician costs. ${ }^{71,79-83}$ Estimates of the direct medical costs of diabetes have increased rapidly over the past few years. ${ }^{50,71}$ Among the factors contributing to the direct costs of diabetes overall, inpatient health care utilization consumes the largest portion (greater than $60 \%$ ) of total health care expenditures. ${ }^{71,79}$ In 1997, the direct medical costs for diabetes were estimated at $\$ 44.1$ billion. ${ }^{71}$ A 2002 study more than doubles this figure, estimating direct costs at $\$ 91.8$ billion..$^{50}$

Medication costs have been found to contribute less than $10 \%$ of total health care expenditures related to diabetes ${ }^{79}$ though costs may increase significantly over time, with the onset of major complications. ${ }^{73}$ However, limited research exists on the specific impact of medications on direct costs associated with the disease. In a treatment simulation model, patients who used oral medications and achieved glycemic control, as defined in the model, were found to have average annual costs $\$ 422$ lower than those patients who did not achieve control. ${ }^{84}$ An economic analysis as part of a randomized controlled clinical trial showed that intensive glycemic control was a cost-effective means of delaying the onset of complications, with a cost reduction of $\$ 1,862$ associated with each year spent free of complications. ${ }^{85}$ The average total cost per patient of standard medical practice has been estimated to decrease by approximately $\$ 438$ with use of an oral medication (metformin), compared with conventional treatment (primarily diet). ${ }^{86}$ And a study that investigated the impact of various treatment methods on total direct costs found that treatment with a class of oral medications-sulfonylureas-lowered the annual costs over no treatment by $\$ 213 .{ }^{87}$ 
The impact of diabetes on workplace productivity. Significantly fewer studies have been conducted to investigate the indirect costs of diabetes and type 2 diabetes in particular. ${ }^{50,71,82,88}$ Although not specific to type 2 diabetes, a number of studies have assessed the economic implications of work disability and productivity losses for individuals with all types of diabetes. ${ }^{71,89-93}$ In particular, work disability, whether measured in days or in quarters, has been shown to be substantially impacted by diabetes..$^{50,90,92,93}$ In 2002, indirect costs attributable to diabetes in general, as measured by restricted or lost work, premature mortality, and permanent disability, were quantified as $\$ 10,759, \$ 21,558$, and $\$ 7,494$ billion, respectively-amounting to $\$ 39,810$ billion in total indirect costs. ${ }^{50}$

Relatively recent results from an evaluation of the health economic benefit of improvement in glycemic control in patients with type 2 diabetes point to significantly favorable health economic outcomes in the form of higher retained employment, greater productive capacity, decreased absenteeism, fewer bed-days, and fewer restricted-activity days. ${ }^{88}$ The savings realized in the study were $\$ 304$ per 1,000 person days for bed-days and $\$ 1,615$ per 1,000 person days for restricted activity days. It has also been shown that diabetes medication in general contributes to large savings in terms of work days for employees with the disease, with an average of 16 days saved because of treatment, taking compliance rates into account. ${ }^{91}$ This translates into a net savings to employers of $\$ 1,475$, in 1996 dollars. Additionally, individuals on blood glucose-lowering agents who are able to achieve better glycemic control have been demonstrated to have fewer physical symptoms and enhanced well-being, ${ }^{94}$ as well as having a significantly reduced risk of having cardiovascular and microvascular complications, ${ }^{95,96}$ although the risks of hypoglycemia must be balanced against the benefits of tight control. 57

Evidence points to the value of early intervention and tight glycemic control in helping to delay or reduce the long-term consequences of diabetes, and significant research has been aimed at describing and identifying interventions that could accomplish these goals. ${ }^{81,84,89,97,98}$ Because the cost of complications may greatly increase the costs of health care utilization for individuals with diabetes, ${ }^{73}$ one focus of interventions is on the prevention and management of such complications. Research has suggested that interventions aimed at preventing one individual's complications related to renal disease would result in total economic savings of $\$ 60,000$ over three years. ${ }^{81}$ In the management of type 2 diabetes and in the avoidance of complications leading to both direct and indirect costs, oral medications play an integral part. ${ }^{97,98}$

\section{Heart failure}

The lifetime risk of developing heart failure for both men and women has been estimated at $20 \%$ (1 in 5). ${ }^{99}$ While heart failure is most prevalent in people over the age of 65 years, prevalence in the 55-64 year age range is 3\% for women and $5 \%$ for men. ${ }^{100}$ Risk factors associated with early onset of heart failure (such as obesity, high blood cholesterol, and hypertension) are on the rise in working adults (35-64 years old), raising concerns of increased incidence of heart failure in younger people.

The total direct costs of heart failure are predicted to exceed $\$ 22.1$ billion in 2003. ${ }^{101}$ While total costs include the costs of hospitalizations, physicians' office visits, nursing home stays, home health care, and pharmacotherapy, ${ }^{101}$ the main cost drivers are frequent hospitalizations and readmissions. ${ }^{102}$ Readmission costs account for almost $30 \%$ of total inpatient care costs. ${ }^{103}$

In his discourse on the economic burden of heart failure, $\mathrm{O}^{\prime}$ Connell ${ }^{104}$ estimates that " . . if pharmacologic and behavioral approaches were combined (in the management of the condition), the five-year mortality rate could be reduced by as much as 50 percent." There is no cure for heart failure. The goals of treatment are to relieve symptoms, enhance functional capacity, and improve survival, while reducing costs related to hospitalizations. ${ }^{105}$

Impact of heart failure drug therapy on health care utilization and direct costs. Reducing the rate of hospitalization and readmission is recog- 
nized as the key to decreasing the cost of care for heart failure. ${ }^{106-109}$ Multiple clinical trials suggest that use of appropriate drug therapies may be the most effective way to reduce the cost of care while reducing morbidity and mortality: Drug therapies can reduce hospitalization from $12 \%$ to $35 \%$, depending on the agent. ${ }^{110-112}$ Drugs like angiotensin converting enzyme (ACE) inhibitors and beta blockers have proved not only to slow the pathophysiological processes involved in heart failure, relieve symptoms, and improve survival, but also to reduce hospital days and readmissions in all stages of heart failure. ${ }^{113-125}$ In fact, ACE inhibitors, beta blockers, diuretics, and digoxin have recently been recommended as first-line pharmacotherapy for heart failure by the American College of Cardiology and the American Heart Association. ${ }^{115}$

ACE inhibitors have demonstrated a potential net savings of $\$ 36$ million due to reduction in hospitalization. ${ }^{113,126}$ For instance, the ACE inhibitor ramipril has been shown to decrease heart failure hospitalizations by $12 \% .{ }^{111}$ The SOLVD trial demonstrated that the enalapril group had a $26 \%$ reduction in the risk of death or hospitalization for worsening heart failure compared with the placebo group. ${ }^{127}$ One cost consequence analysis, based on clinical trial results, ${ }^{128}$ has shown that use of the ACE inhibitor fosinopril achieved an overall cost savings of $\$ 1.6$ million per 1,000 patients. ${ }^{129,130}$ Another study, a cost-effectiveness analysis of the ACE inhibitor captopril for heart failure patients, using SAVE data, found that use of captopril therapy resulted in a cost per life year saved of $\$ 1,460 .^{131}$

The literature also contains a number of compelling studies describing the impact of beta-blocker therapy on utilization, overall medical costs, and survival of patients with heart failure. Clinical trials have demonstrated that carvedilol therapy reduced mortality by $65 \%$ and hospital admissions by $22 \%$, and reduced overall costs of care by approximately \$14,530. ${ }^{132-134}$ A study using data from the US Carvedilol Heart Failure Trials Program has also shown that carvedilol reduced the risk of hospitalization for any reason by $29 \%$, the risk of cardiovascular hospitalization by $28 \%$, the risk of heart failure hospitalization by $38 \%$, and the mean number of hospitalizations for heart failure by $53 \% .{ }^{135}$ These studies have also documented that the cost per life-year saved for carvedilol was $\$ 29,477$ under limited benefits assumptions and $\$ 12,799$ under extended benefits assumptions. ${ }^{136}$ A number of other studies have similarly demonstrated the effectiveness of beta-blockers carvedilol and bisoprolol in reducing the rate of hospitalization and the cost of care. ${ }^{120,133,137-139}$

A common problem in the care for patients with heart failure is the underprescription and underuse of appropriate drugs such as ACE inhibitors and beta blockers. ${ }^{140-144}$ For instance, only slightly more than $50 \%$ of heart failure patients receive ACE inhibitor therapy, while patients at all levels of severity should be receiving it. ${ }^{144}$ Therefore, an objective of cardiovascular quality improvement and disease management programs should be to increase the use of such life-saving and cost-effective treatment regimens.

The impact of heart failure on workplace productivity. The published literature on the impact of heart failure on workplace productivity is limited. This may be attributable in part to the relatively new science of productivity measurement, and to the significantly higher prevalence of diagnosed heart failure in the older, non-working population. In a 2001 report $^{145}$ the National Committee for Quality Assurance (NCQA) applied its economic model to estimate the number of working people with heart disease who are enrolled in health plans that provide Health Plan Employer Data and Information Set $\left(\right.$ HEDIS $^{\circledR}$ ) data (also see http:// www.ncqa.org). The NCQA compared the indirect costs associated with heart failure for its accredited health plans (that is, health plans that meet minimum treatment standards for heart disease) and non-accredited health plans. They reported that, for a population of $1,248,304$ workers with heart disease (based on prevalence data), a total of 2,917,000 missed or unproductive workdays were avoided and $\$ 501,000,000$ in sick-day wages was saved by the accredited health plans that provided the appropriate outpatient treatments for patients diagnosed with heart disease. ${ }^{145}$ 


\section{Migraine}

Migraine headache is a highly prevalent ${ }^{146}$ chronic condition, which manifests as acute episodes. Migraine is frequently misdiagnosed $^{147}$ and undertreated. ${ }^{148}$ The prevalence of migraine headache is three times as high for women as it is for men (18\% vs. $6 \%) .{ }^{149}$ The highest prevalence of migraine occurs between ages 25 and 44 years, a time when many women are highly productive in their professional career, family responsibilities, and social life. ${ }^{149}$

The direct and indirect costs of migraine headache in the United States are significant. In 1994, the associated health care costs for migraine headache were approximately $\$ 1$ billion. ${ }^{150}$ Estimates range from $\$ 17$ billion in 1986 to $\$ 13$ billion in 1994 for annual losses associated with lost workplace productivity secondary to migraine headache. ${ }^{150,151}$ A 1998 survey comparing patients with and without migraine found that over a 6-month period, patients with migraine had higher direct medical costs (by \$107), due largely to greater frequency of physician and ED visits, and greater lost productivity, for a total incremental 6-month cost of migraine of $\$ 313$. $^{152}$ Another study estimated the annual employer cost of migraine associated with lost productivity at $\$ 3,309$ per migraine. ${ }^{153}$

Fortunately, significant advances have been made in migraine pharmacotherapy, with the availability of the triptans, a class of drugs introduced in the 1990s. A large number of studies have demonstrated improvement in patients' health-related quality of life ${ }^{154-161}$ and reductions in patients' lost workplace productivity associated with initiation of triptan therapy. ${ }^{155-157,162-164}$ These improvements are clearly of importance to the individual with migraine headaches. However, employers and health care purchasers would be interested in knowing whether the benefit(s) of a migrainespecific medication (ie, decreased medical costs, decreased lost workplace productivity) are greater than its associated costs, thus potentially offsetting the cost of migraine therapy and producing a net benefit from the employer's economic perspective.

Impact of migraine drug therapy on health care utilization and direct costs. A recent literature re- view by Caro and Getsios ${ }^{165}$ demonstrates that a large number of investigations have examined the impact of triptan therapy on health care use and the associated direct costs of individuals with migraine headache. Most of these studies specifically evaluated sumatriptan, the first commercially available triptan, and a widely used migraine pharmacotherapy, although several other triptans have since become available. The majority of investigations have demonstrated that sumatriptan therapy is associated with reductions in health care use. For example, a prospective, observational study examining the change in health care use of 178 patients with migraine in a managed care organization found significant decreases in the mean number of physician office visits, ED visits, and medical procedures in the six months after sumatriptan therapy was initiated. ${ }^{166} \mathrm{Be}-$ cause the triptans are more expensive than traditional non-triptan therapies, some studies have indicated that net direct medical costs may increase following initiation of triptan therapy. However, these studies generally have not considered the non-medical and indirect cost savings associated with improvement in appropriate management, and reduction in medical utilization.

The impact of migraine on workplace productivity. Many studies have demonstrated that triptan therapy is associated with reductions in time lost from work and non-work activities, and their associated indirect costs. ${ }^{165}$ In an investigation examining the differences in time lost from work and non-work activity before and after the initiation of sumatriptan therapy, Lofland et al ${ }^{166}$ showed that, on average, the number of workdays missed due to migraine decreased by 0.5 days and 0.7 days in the three and six months, respectively, after starting sumatriptan. In addition, individuals reported working on average four days with migraine symptoms in the three months before starting sumatriptan, but six months after the initiation of sumatriptan this had decreased to two days. A cost-effectiveness and cost-benefit analysis of data from this study ${ }^{167}$ showed an overall net cost savings after sumatriptan therapy initiation of $\$ 1,249$, and an incremental cost-effectiveness ratio of $\$ 25$ for each additional mi- 
graine-disability-day avoided. Biddle et al ${ }^{168}$ demonstrated through a decision tree analysis an annual incremental net benefit of sumatriptan over usual therapy of $\$ 114-\$ 540$ per patient, with the higher costs of sumatriptan (in comparison with usual therapy) being offset by reductions in health care use and lost productivity. Other researchers, including Caro et $\mathrm{al}^{169}$ have demonstrated similar net savings.

\section{DISCUSSION}

Four chronic conditions were considered in this literature review, which sought to summarize key published studies on the epidemiology and economic impact of these conditions, with a focus on the economic impact of pharmacotherapy on total direct medical cost and workplace productivity. Care guidelines for asthma, diabetes, heart failure, and migraine all emphasize the critical role of pharmaceuticals in managing these conditions. This review provides support for the role of pharmaceuticals in managing clinical, humanistic, and economic outcomes.

These findings may be helpful to employers who are considering offering a pharmacy benefit or restructuring existing benefits. This review did not investigate the extent to which different levels of benefits (eg, tiered benefits with different levels of co-payments) foster or impede the likelihood that patients will be prescribed appropriate therapy, and will fill prescriptions and adhere to provider recommendations. However, we do demonstrate that the literature suggests a consistent benefit to employers-in regard to both direct medical cost savings and avoided losses to workplace productivity - in making appropriate pharmacotherapy available to employees (at least for these four prevalent and costly chronic conditions).

The findings are limited to published studies. It is possible that "publication bias," in which only findings in favor of certain medications get published, overestimates the contribution of pharmacotherapy to cost management for the four conditions studied. This review also focused on key studies with measurement of economic outcomes; it is possible that some relevant studies either were not iden- tified through this review or that economic data in contrast with the findings cited above were not included in the review. However, all relevant identified articles, whether they supported or refuted the hypothesis of the economic benefit of appropriate pharmacotherapy, were reviewed and are cited as appropriate. The focus of this review also was on the appropriate use of pharmacotherapy. Real world effectiveness and cost-effectiveness may be mitigated by patient adherence and other factors that may be encountered less frequently in the research environment. The cost savings associated with appropriate pharmaceutical use also are sensitive to changes in drug pricing. Furthermore, few of the studies discussed examined utilization and costs in the long term, beyond one or two years. Despite these concerns, a large majority of published evidence makes a compelling case for the potential economic benefit of appropriate pharmacotherapy in accordance with current care guidelines.

Finally, much research remains to be done to better establish the linkages between pharmacotherapy and workplace productivity. The science of productivity measurement is still developing, and controversy about which approach is most appropriate (eg, human capital, friction cost, or other approaches) continues. Measurement of presenteeism also is a developing field. The early evidence identified in this literature review suggests direct relationships between appropriate drug use and workplace productivity, but additional high-quality studies are needed.

\section{CONCLUSIONS}

The findings of this review strengthen the arguments for appropriate pharmacotherapy as a cornerstone for disease management efforts. Employers should be concerned with ensuring that employees have access to needed medications, and are educated and supported so as to be adherent to provider recommendations. Appropriate pharmaceutical agents help to counter the detrimental effects of chronic conditions on patients, thereby improving health status, reducing utilization of higher cost health care resources, and decreasing time lost 
from workplace productivity. The evidence suggests that increased costs for disease-specific pharmaceutical therapy, in accordance with current care guidelines, may be offset by savings in a combination of direct and indirect medical costs.

\section{ACKNOWLEDGMENTS}

This literature review was funded by GlaxoSmithKline, under a subcontract from Interactive Forums, Inc. The authors appreciate the guidance of Harry Leider, M.D., at Interactive Forums, Joseph Fuhr, Ph.D., a consulting economist at Widener University, and Jennifer Lofland, Pharm.D., and David B. Nash, M.D., M.B.A., at Thomas Jefferson University.

\section{REFERENCES}

1. Levit K, Smith C, Cowan C, Lazenby H, Sensenig A, Catlin A. TRENDS: trends in U.S. health care spending, 2001. Health Aff (Millwood) 2003;22:154-164.

2. Najib MM, Goldberg Arnold RJ, Kaniecki DJ, et al. Medical resource use and costs of congestive heart failure after carvedilol use. Heart Dis 2002;4:70-77.

3. National Asthma Education and Prevention Program. Expert Panel Report II: Guidelines for the diagnosis and management of asthma. Publication 974051. Bethesda, MD: National Institutes of Health, 1997.

4. Global Initiative for Asthma. Global strategy for asthma management and prevention. Publication 023659. Bethesda, MD: National Institutes of Health, 2002. Available online at: http://www.ginasthma. com; accessed March 2003.

5. Akinbami LJ, Schoendorf KC. Trends in childhood asthma: prevalence, health care utilization, and mortality. Pediatrics 2002;110:315-322.

6. Mannino DM, Homa DM, Akinbami LJ, Moorman JE, Gwynn C, Redd SC. Surveillance for asthmaUnited States, 1980-1999. MMWR Surveill Summ 2002;51(1):1-13.

7. American Lung Association. Trends in asthma morbidity and mortality. Available online at: http:// www.lungusa.org/data/asthma/ASTHMAdt.pdf; accessed March 2003.

8. Hall MJ, Owings MF. 2000 National Hospital Discharge Survey. Adv Data 2002;(329):1-18.

9. Weiss KB, Sullivan SD. The health economics of asthma and rhinitis. I. Assessing the economic impact. J Allergy Clin Immunol 2001;107:3-8.

10. Smith DH, Malone DC, Lawson KA, Okamoto LJ, Battista C, Saunders WB. A national estimate of the economic costs of asthma. Am J Respir Crit Care Med 1997;156:787-793.

11. Adams RJ, Fuhlbrigge A, Finkelstein JA, et al. Impact of inhaled antiinflammatory therapy on hospitalization and emergency department visits for children with asthma. Pediatrics 2001;107:706-711.

12. Finkelstein JA, Lozano P, Farber HJ, Miroshnik I, Lieu TA. Underuse of controller medications among Medicaid-insured children with asthma. Arch Pediatr Adolesc Med 2002;156:562-567.

13. Donahue JG, Fuhlbrigge AL, Finkelstein JA, et al. Asthma pharmacotherapy and utilization by children in 3 managed care organizations. The Pediatric Asthma Care Patient Outcomes Research Team. J Allergy Clin Immunol 2000;106:1108-1114.

14. Staresinic AG, Sorkness CA. The use of inhaled corticosteroids in adult asthma. Med Clin North Am 2002;86:1035-1047.

15. National Asthma Education and Prevention Program. Expert Panel Report: Guidelines for the diagnosis and management of asthma update on selected topics-2002. J Allergy Clin Immunol 2002;110 (Suppl):S141-S219.

16. Suissa S, Ernst P. Inhaled corticosteroids: impact on asthma morbidity and mortality. J Allergy Clin Immunol 2001;107:937-944.

17. Blais L, Suissa S, Boivin JF, Ernst P. First treatment with inhaled corticosteroids and the prevention of admissions to hospital for asthma. Thorax 1998;53: 1025-1029.

18. Gerdtham UG, Hertzman P, Jonsson B, Boman G. Impact of inhaled corticosteroids on acute asthma hospitalization in Sweden 1978 to 1991. Med Care 1996;34:1188-1198.

19. Wennergren G, Kristjansson S, Strannegard IL. Decrease in hospitalization for treatment of childhood asthma with increased use of antiinflammatory treatment, despite an increase in prevalence of asthma. J Allergy Clin Immunol 1996;97:742-748.

20. Schatz M, Cook EF, Nakahiro R, Petitti D. Inhaled corticosteroids and allergy specialty care reduce emergency hospital use for asthma. J Allergy Clin Immunol 2003;111:503-508.

21. Donahue JG, Weiss ST, Livingston JM, Goetsch MA, Greineder DK, Platt R. Inhaled steroids and the risk of hospitalization for asthma. JAMA 1997;277:887891.

22. Sin DD, Man SF. Low-dose inhaled corticosteroid therapy and risk of emergency department visits for asthma [comment]. Arch Intern Med 2002;162: 1591-1595.

23. Sin DD, Tu JV. Inhaled corticosteroid therapy reduces the risk of rehospitalization and all-cause mortality in elderly asthmatics. Eur Respir J 2001;17:380385.

24. Suissa S, Ernst P, Benayoun S, Baltzan M, Cai B. Lowdose inhaled corticosteroids and the prevention of death from asthma. N Engl J Med 2000;343:332-336.

25. Goldman M, Rachmiel M, Gendler L, Katz Y. Decrease in asthma mortality rate in Israel from 
1991-1995: is it related to increased use of inhaled corticosteroids? J Allergy Clin Immunol 2000;105: 71-74.

26. Balkrishnan R, Norwood GJ, Anderson A. Outcomes and cost benefits associated with the introduction of inhaled corticosteroid therapy in a Medicaid population of asthmatic patients. Clin Ther 1998;20:567580.

27. Shireman TI, Heaton PC, Gay WE, Cluxton RJ, Moomaw CJ. Relationship between asthma drug therapy patterns and healthcare utilization. Ann Pharmacother 2002;36:557-564.

28. Piecoro LT, Potoski M, Talbert JC, Doherty DE. Asthma prevalence, cost, and adherence with expert guidelines on the utilization of health care services and costs in a state Medicaid population. Health Serv Res 2001;36:357-371.

29. Van Ganse E, Laforest L, Pietri G, et al. Persistent asthma: disease control, resource utilisation and direct costs. Eur Respir J 2002;20:260-267.

30. MacKinnon NJ, Flagstad MS, Peterson CR, MeschBeatty K. Disease management program for asthma: baseline assessment of resource use. Am J Health Syst Pharm 1996;53:535-541.

31. Paltiel AD, Fuhlbrigge AL, Kitch BT, et al. Cost-effectiveness of inhaled corticosteroids in adults with mild-to-moderate asthma: results from the asthma policy model. J Allergy Clin Immunol 2001;108:39-49.

32. Ungar WJ, Coyte PC. Measuring productivity loss days in asthma patients. The Pharmacy Medication Monitoring Program and Advisory Board. Health Econ 2000;9:37-46.

33. Birnbaum HG, Berger WE, Greenberg PE, et al. Direct and indirect costs of asthma to an employer. J Allergy Clin Immunol 2002;109:264-270.

34. Erickson SR, Kirking DM. A cross-sectional analysis of work-related outcomes in adults with asthma. Ann Allergy Asthma Immunol 2002;88:292-300.

35. Diette GB, Markson L, Skinner EA, Nguyen TT, Algatt-Bergstrom $\mathrm{P}, \mathrm{Wu} \mathrm{AW}$. Nocturnal asthma in children affects school attendance, school performance, and parents' work attendance. Arch Pediatr Adolesc Med 2000;154:923-928.

36. Blanc PD, Cisternas M, Smith S, Yelin EH. Asthma, employment status, and disability among adults treated by pulmonary and allergy specialists [comment]. Chest 1996;109:688-696.

37. Ungar WJ, Coyte PC. Prospective study of the patient-level cost of asthma care in children. Pediatr Pulmonol 2001;32:101-108.

38. Blanc PD, Trupin L, Eisner M, et al. The work impact of asthma and rhinitis: findings from a population-based survey. J Clin Epidemiol 2001;54:610-618.

39. Ford ES, Mannino DM, Homa DM, et al. Self-reported asthma and health-related quality of life. Chest 2003;123:119-127.

40. Wolfenden LL, Diette GB, Krishnan JA, Skinner EA, Steinwachs DM, Wu AW. Lower physician estimate of underlying asthma severity leads to undertreatment. Arch Intern Med 2003;163:231-236.
41. Bateman ED, Frith LF, Braunstein GL. Achieving guideline-based asthma control: does the patient benefit? Eur Respir J 2002;20:588-595.

42. Delaronde S. Using case management to increase antiinflammatory medication use among a managed care population with asthma. J Asthma 2002;39:5563.

43. Burton WN, Connerty CM, Schultz AB, Chen CY, Edington DW. Bank One's worksite-based asthma disease management program. J Occup Environ Med 2001;43:75-82.

44. Knoell DL, Pierson JF, Marsh CB, Allen JN, Pathak DS. Measurement of outcomes in adults receiving pharmaceutical care in a comprehensive asthma outpatient clinic. Pharmacotherapy 1998;18:1365-1374.

45. Legorreta AP, Leung KM, Berkbigler D, Evans R, Liu $X$. Outcomes of a population-based asthma management program: quality of life, absenteeism, and utilization [comment]. Ann Allergy Asthma Immunol 2000;85:28-34.

46. Lucas DO, Zimmer LO, Paul JE, et al. Two-year results from the asthma self-management program: long-term impact on health care services, costs, functional status, and productivity [see comments]. J Asthma 2001;38:321-330.

47. Higgins JC, Kiser WR, McClenathan S, Tynan NL. Influence of an interventional program on resource use and cost in pediatric asthma. Am J Manag Care 1998;4:1465-1469.

48. Mokdad AH, Ford ES, Bowman BA, et al. Prevalence of obesity, diabetes, and obesity-related health risk factors, 2001. JAMA 2003;289:76-79.

49. King H, Aubert RE, Herman WH. Global burden of diabetes, 1995-2025: prevalence, numerical estimates, and projections. Diabetes Care 1998;21:14141431.

50. Hogan P, Dall T, Nikolov P. Economic costs of diabetes in the US in 2002. Diabetes Care 2003;26: 917-932.

51. Eastman RC, Javitt JC, Herman WH, et al. Model of complications of NIDDM. II. Analysis of the health benefits and cost-effectiveness of treating NIDDM with the goal of normoglycemia. Diabetes Care 1997;20:735-744.

52. Resnick HE, Howard BV. Diabetes and cardiovascular disease. Annu Rev Med 2002;53:245-267.

53. Haffner SM. Management of dyslipidemia in adults with diabetes. Diabetes Care 1998;21:160-178.

54. Harris MI. Diabetes in America: epidemiology and scope of the problem. Diabetes Care 1998;21(Suppl 3):C11-C14.

55. Foster RH, Plosker GL. Glipizide. A review of the pharmacoeconomic implications of the extended-release formulation in type 2 diabetes mellitus. Pharmacoeconomics 2000;18:289-306.

56. Clark CM Jr. The burden of chronic hyperglycemia. Diabetes Care 1998;21(Suppl 3):C32-C34.

57. Standards of medical care for patients with diabetes mellitus. Diabetes Care 2003;26(Suppl1):S33-S50.

58. Tight blood pressure control and risk of macrovas- 
cular and microvascular complications in type 2 diabetes: UKPDS 38. UK Prospective Diabetes Study Group. BMJ 1998;317:703-713.

59. Klein R, Klein BE. Relation of glycemic control to diabetic complications and health outcomes. Diabetes Care 1998;21(Suppl3):C39-C43.

60. Testa MA, Simonson DC, Turner RR. Valuing quality of life and improvements in glycemic control in people with type 2 diabetes. Diabetes Care 1998; 21(Suppl 3):C44-C52.

61. Caldwell EM, Baxter J, Mitchell CM, Shetterly SM, Hamman RF. The association of non-insulin-dependent diabetes mellitus with perceived quality of life in a biethnic population: the San Luis Valley Diabetes Study. Am J Public Health 1998;88:1225-1229.

62. Von Korff M, Gruman J, Schaefer J, Curry SJ, Wagner EH. Collaborative management of chronic illness. Ann Intern Med 1997;127:1097-1102.

63. Muhlhauser I, Berger M. Evidence-based patient information in diabetes. Diabet Med 2000;17:823-829.

64. Sidorov J, Shull R, Tomcavage J, Girolami S, Lawton $\mathrm{N}$, Harris R. Does diabetes disease management save money and improve outcomes? A report of simultaneous short-term savings and quality improvement associated with a health maintenance organization-sponsored disease management program among patients fulfilling Health Employer Data and Information Set criteria. Diabetes Care 2002;25:684689.

65. Koproski J, Pretto Z, Poretsky L. Effects of an intervention by a diabetes team in hospitalized patients with diabetes. Diabetes Care 1997;20:1553-1555.

66. Turner RC, Cull CA, Frighi V, Holman RR. Glycemic control with diet, sulfonylurea, metformin, or insulin in patients with type 2 diabetes mellitus: progressive requirement for multiple therapies (UKPDS 49). UK Prospective Diabetes Study (UKPDS) Group. JAMA 1999;281:2005-2012.

67. Leaf E, King JO. Patient outcomes after formulary conversion from immediate-release to extended-release glipizide tablets. Am J Health Syst Pharm 1999;56:454-456.

68. Dailey G, Kim MS, Lian JF. Patient compliance and persistence with antihyperglycemic drug regimens: evaluation of a Medicaid patient population with type 2 diabetes mellitus. Clin Ther 2001;23:13111320.

69. Beckles GL, Engelgau MM, Narayan KM, Herman WH, Aubert RE, Williamson DF. Population-based assessment of the level of care among adults with diabetes in the U.S. Diabetes Care 1998;21:1432-1438.

70. Melikian C, White TJ, Vanderplas A, Dezii CM, Chang E. Adherence to oral antidiabetic therapy in a managed care organization: a comparison of monotherapy, combination therapy, and fixed-dose combination therapy. Clin Ther 2002;24:460-467.

71. Economic consequences of diabetes mellitus in the U.S. in 1997. American Diabetes Association. Diabetes Care 1998;21:296-309.

72. Bhattacharyya SK, Else BA. Medical costs of man- aged care in patients with type 2 diabetes mellitus. Clin Ther 1999;21:2131-2142.

73. Brown JB, Nichols GA, Glauber HS, Bakst AW. Type 2 diabetes: incremental medical care costs during the first 8 years after diagnosis. Diabetes Care 1999;22: 1116-1124.

74. Brown JB, Pedula KL, Bakst AW. The progressive cost of complications in type 2 diabetes mellitus. Arch Intern Med 1999;159:1873-1880.

75. Caro JJ, Ward AJ, O'Brien JA. Lifetime costs of complications resulting from type 2 diabetes in the U.S. Diabetes Care 2002;25:476-481.

76. Kangas T, Aro S, Koivisto VA, Salinto M, Laakso M, Reunanen A. Structure and costs of health care of diabetic patients in Finland. Diabetes Care 1996;19: 494-497.

77. Nichols GA, Glauber HS, Brown JB. Type 2 diabetes: incremental medical care costs during the 8 years preceding diagnosis. Diabetes Care 2000;23:16541659.

78. O’Brien JA, Shomphe LA, Kavanagh PL, Raggio G, Caro JJ. Direct medical costs of complications resulting from type 2 diabetes in the U.S. Diabetes Care 1998;21:1122-1128.

79. Rubin RJ, Altman WM, Mendelson DN. Health care expenditures for people with diabetes mellitus, 1992. J Clin Endocrinol Metab 1994;78:809A-809F.

80. Gray A, Clarke P, Farmer A, Holman R. Implementing intensive control of blood glucose concentration and blood pressure in type 2 diabetes in England: cost analysis (UKPDS 63). BMJ 2002;325:860.

81. Guo JJ, Gibson JT, Gropper DM, Oswald SL, Barker $\mathrm{KN}$. Empiric investigation on direct costs-of-illness and healthcare utilization of Medicaid patients with diabetes mellitus. Am J Manag Care 1998;4:14331446.

82. Herman WH, Eastman RC. The effects of treatment on the direct costs of diabetes. Diabetes Care 1998;21(Suppl 3):C19-C24.

83. Redekop WK, Koopmanschap MA, Rutten GE, Wolffenbuttel BH, Stolk RP, Niessen LW. Resource consumption and costs in Dutch patients with type 2 diabetes mellitus. Results from 29 general practices. Diabet Med 2002;19:246-253.

84. Ramsdell JW, Grossman JA, Stephens JM, Botteman MF, Arocho R. A short-term cost-of-treatment model for type 2 diabetes: comparison of glipizide gastrointestinal therapeutic system, metformin, and acarbose. Am J Manag Care 1999;5:1007-1024.

85. Gray A, Raikou M, McGuire A, et al. Cost effectiveness of an intensive blood glucose control policy in patients with type 2 diabetes: economic analysis alongside randomised controlled trial (UKPDS 41). United Kingdom Prospective Diabetes Study Group. BMJ 2000;320:1373-1378.

86. Clarke P, Gray A, Adler A, et al. Cost-effectiveness analysis of intensive blood-glucose control with metformin in overweight patients with type II diabetes (UKPDS No. 51). Diabetologia 2001;44:298-304.

87. Brown JB, Nichols GA, Glauber HS, Bakst AW, Scha- 
effer M, Kelleher CC. Health care costs associated with escalation of drug treatment in type 2 diabetes mellitus. Am J Health Syst Pharm 2001;58:151-157.

88. Testa MA, Simonson DC. Health economic benefits and quality of life during improved glycemic control in patients with type 2 diabetes mellitus: a randomized, controlled, double-blind trial. JAMA 1998;280:1490-1496.

89. Licciardone JC, Kotsanos JG, Brinkman-Kaplan V, Cooper T, Jordan JE, Wishner KL. Resource utilization and work or school loss reported by patients with diabetes: experience in diabetes training programs. Am J Manag Care 1997;3:777-782.

90. Mayfield JA, Deb P, Whitecotton L. Work disability and diabetes. Diabetes Care 1999;22:1105-1109.

91. Rizzo JA, Abbott TA III, Pashko S. Labour productivity effects of prescribed medicines for chronically ill workers. Health Econ 1996;5:249-265.

92. Skerjanc A. Sickness absence in diabetic employees. Occup Environ Med 2001;58:432-436.

93. Valdmanis V, Smith DW, Page MR. Productivity and economic burden associated with diabetes. Am J Public Health 2001;91:129-130.

94. Van der Does FE, De Neeling JN, Snoek FJ, et al. Symptoms and well-being in relation to glycemic control in type II diabetes. Diabetes Care 1996;19: 204-210.

95. Gaede P, Vedel P, Larsen N, Jensen GV, Parving HH, Pedersen O. Multifactorial intervention and cardiovascular disease in patients with type 2 diabetes. $\mathrm{N}$ Engl J Med 2003;348:383-393.

96. Intensive blood-glucose control with sulphonylureas or insulin compared with conventional treatment and risk of complications in patients with type 2 diabetes (UKPDS 33). UK Prospective Diabetes Study (UKPDS) Group. Lancet 1998;352:837-853.

97. Holmboe ES. Oral antihyperglycemic therapy for type 2 diabetes: clinical applications. JAMA 2002; 287:373-376.

98. Palumbo PJ. Gycemic control, mealtime glucose excursions, and diabetic complications in type 2 diabetes mellitus. Mayo Clin Proc 2001;76:609-618.

99. Lloyd-Jones DM, Larson MG, Leip EP, et al. Lifetime risk for developing congestive heart failure: the Framingham Heart Study [comment]. Circulation 2002;106:3068-3072.

100. Adams KF Jr. New epidemiologic perspectives concerning mild-to-moderate heart failure. Am J Med 2001;110(Suppl7A):6S-13S.

101. American Heart Association. Heart disease and stroke statistics-2003 update. Dallas: American Heart Association, 2002.

102. Jerant AF, Azari R, Nesbitt TS. Reducing the cost of frequent hospital admissions for congestive heart failure: a randomized trial of a home telecare intervention. Med Care 2001;39:1234-1245.

103. Fleg JL, Hinton PC, Lakatta EG, et al. Physician utilization of laboratory procedures to monitor outpatients with congestive heart failure. Arch Intern Med 1989;149:393-396.
104. O'Connell JB. The economic burden of heart failure. Clin Cardiol 2000;23:III6-III10.

105. Goldberg RJ, Meyer TE. Advances and stagnations in heart failure. Arch Intern Med 1997;157:17-19.

106. Cline CM, Israelsson BY, Willenheimer RB, Broms K, Erhardt LR. Cost effective management programme for heart failure reduces hospitalisation. Heart 1998;80:442-446.

107. Krumholz HM, Chen YT, Bradford WD, Cerese J. Variations in and correlates of length of stay in academic hospitals among patients with heart failure resulting from systolic dysfunction. Am J Manag Care 1999;5:715-723.

108. Linne $\mathrm{AB}$, Liedholm $\mathrm{H}$, Jendteg $\mathrm{S}$, Israelsson $\mathrm{B}$. Health care costs of heart failure: results from a randomised study of patient education. Eur J Heart Fail 2000;2:291-297.

109. Stewart S, Marley JE, Horowitz JD. Effects of a multidisciplinary, home-based intervention on unplanned readmissions and survival among patients with chronic congestive heart failure: a randomised controlled study. Lancet 1999;354:1077-1083.

110. Riegel B, Carlson B, Kopp Z, LePetri B, Glaser D, Unger A. Effect of a standardized nurse case-management telephone intervention on resource use in patients with chronic heart failure. Arch Intern Med 2002;162:705-712.

111. Yusuf S, Sleight P, Pogue J, Bosch J, Davies R, Dagenais $\mathrm{G}$. Effects of an angiotensin-converting-enzyme inhibitor, ramipril, on cardiovascular events in high-risk patients. The Heart Outcomes Prevention Evaluation Study Investigators. $N$ Engl J Med 2000;342:145-153.

112. Pitt B, Zannad F, Remme WJ, et al. The effect of spironolactone on morbidity and mortality in patients with severe heart failure. Randomized Aldactone Evaluation Study Investigators. N Engl J Med 1999;341:709-717.

113. Berry C, Murdoch DR, McMurray JJ. Economics of chronic heart failure. Eur J Heart Fail 2001;3:283-291.

114. Cleland JG. Health economic consequences of the pharmacological treatment of heart failure. Eur Heart J 1998;19(Suppl P):32-39.

115. Doggrell SA, Brown L. Present and future pharmacotherapy for heart failure. Expert Opin Pharmacother 2002;3:915-930.

116. Eccles M, Freemantle N, Mason J. North of England evidence based development project: guideline for angiotensin converting enzyme inhibitors in primary care management of adults with symptomatic heart failure. BMJ 1998;316:1369-1375.

117. Hart W, Rhodes G, McMurray J. The cost effectiveness of enalapril in the treatment of chronic heart failure. Br J Med Econ 2003;6:91-98.

118. Krum H, Roecker EB, Mohacsi P, et al. Effects of initiating carvedilol in patients with severe chronic heart failure: results from the COPERNICUS Study. JAMA 2003;289:712-718.

119. Levy E. From cost of illness to cost-effectiveness in heart failure. Eur Heart J 1998;19(Suppl P):2-4. 
120. Levy P, Lechat P, Leizorovicz A, Levy E. A cost-minimization of heart failure therapy with bisoprolol in the French setting: an analysis from CIBIS trial data. Cardiac Insufficiency Bisoprolol Study. Cardiovasc Drugs Ther 1998;12:301-305.

121. Packer M, Poole-Wilson PA, Armstrong PW, et al. Comparative effects of low and high doses of the angiotensin-converting enzyme inhibitor, lisinopril, on morbidity and mortality in chronic heart failure. ATLAS Study Group. Circulation 1999;100:23122318.

122. Packer M, Fowler MB, Roecker EB, et al. Effect of carvedilol on the morbidity of patients with severe chronic heart failure: results of the carvedilol prospective randomized cumulative survival (COPERNICUS) study. Circulation 2002;106:2194-2199.

123. Porcu M, Cacciatore G. [Intervention strategies in refractory heart failure]. Ital Heart J 2002;3:791-792.

124. Schadlich PK, Huppertz E, Brecht JG. Cost-effectiveness analysis of ramipril in heart failure after myocardial infarction. Economic evaluation of the Acute Infarction Ramipril Efficacy (AIRE) study for Germany from the perspective of statutory health insurance. Pharmacoeconomics 1998;14:653-669.

125. Sin DD, McAlister FA. The effects of beta-blockers on morbidity and mortality in a population-based cohort of 11,942 elderly patients with heart failure. Am J Med 2002;113:650-656.

126. Mackowiak J. Cost of heart failure to the healthcare system. Am J Manag Care 1998;4(Suppl):S338-S342.

127. Effect of enalapril on survival in patients with reduced left ventricular ejection fractions and congestive heart failure. The SOLVD Investigators. N Engl J Med 1991;325:293-302.

128. Brown EJ Jr, Chew PH, MacLean A, Gelperin K, Ilgenfritz JP, Blumenthal M. Effects of fosinopril on exercise tolerance and clinical deterioration in patients with chronic congestive heart failure not taking digitalis. Fosinopril Heart Failure Study Group. Am J Cardiol 1995;75:596-600.

129. Kleber FX, Niemoller L, Doering W. Impact of converting enzyme inhibition on progression of chronic heart failure: results of the Munich Mild Heart Failure Trial. Br Heart J 1992;67:289-296.

130. Szucs TD. Pharmacoeconomics of angiotensin converting enzyme inhibitors in heart failure. Am J Hypertens 1997;10(Suppl):272S-279S.

131. Pfeffer MA, Braunwald E, Moye LA, et al. Effect of captopril on mortality and morbidity in patients with left ventricular dysfunction after myocardial infarction. Results of the Survival and Ventricular Enlargement Trial. The SAVE Investigators. N Engl J Med 1992;327:669-677.

132. Najib MM, Goldberg ARJ, Kaniecki DJ, et al. Medical resource use and costs of congestive heart failure after carvedilol use. Heart Dis 2002;4:70-77.

133. Packer M, Colucci WS, Sackner-Bernstein JD, et al. Double-blind, placebo-controlled study of the effects of carvedilol in patients with moderate to severe heart failure. The PRECISE Trial. Prospective Ran- domized Evaluation of Carvedilol on Symptoms and Exercise. Circulation 1996;94:2793-2799.

134. Vera-Llonch M, Menzin J, Richner RE, Oster G. Costeffectiveness results from the US Carvedilol Heart Failure Trials Program. Ann Pharmacother 2001;35: 846-851.

135. Fowler MB, Vera-Llonch M, Oster G, et al. Influence of carvedilol on hospitalizations in heart failure: incidence, resource utilization and costs. U.S. Carvedilol Heart Failure Study Group. J Am Coll Cardiol 2001;37:1692-1699.

136. Delea TE, Vera-Llonch M, Richner RE, Fowler MB, Oster G. Cost effectiveness of carvedilol for heart failure. Am J Cardiol 1999;83:890-896.

137. Australia/New Zealand Heart Failure Research Cooperative Group. Randomized, placebo-controlled trial of carvedilol on patients with congestive heart failure. Lancet 1997;349:375-380.

138. Bristow MR, Gilbert EM, Abraham WT, et al. Carvedilol produces dose-related improvements in left ventricular function and survival in subjects with chronic heart failure. MOCHA Investigators. Circulation 1996;94:2807-2816.

139. Colucci WS, Packer M, Bristow MR, et al. Carvedilol inhibits clinical progression in patients with mild symptoms of heart failure. US Carvedilol Heart Failure Study Group. Circulation 1996;94:2800-2806.

140. Andersson F, Cline C, Ryden-Bergsten T, Erhardt L. Angiotensin converting enzyme (ACE) inhibitors and heart failure. The consequences of underprescribing. Pharmacoeconomics 1999;15:535-550.

141. Cline CM, Boman K, Holst M, Erhardt LR. The management of heart failure in Sweden. Eur J Heart Fail 2002;4:373-376.

142. Hobbs FD. Management of heart failure: evidence versus practice. Does current prescribing provide optimal treatment for heart failure patients? Br J Gen Pract 2000;50:735-742.

143. McMurray JJ. Failure to practice evidence-based medicine: why do physicians not treat patients with heart failure with angiotensin-converting enzyme inhibitors? Eur Heart J 1998;19(Suppl L):L15-L21.

144. Remme WJ. Towards the better treatment of heart failure. Eur Heart J 1998;19(Suppl L):L36-L42.

145. National Committee for Quality Assurance. The state of managed care quality, 2001: the business case for quality. Washington, DC: National Committee for Quality Assurance, 2001.

146. Linet MS, Stewart WF, Celentano DD, Ziegler D, Sprecher M. An epidemiologic study of headache among adolescents and young adults. JAMA 1989; 261:2211-2216.

147. Lipton RB, Stewart WF, Celentano DD, Reed ML. Undiagnosed migraine headaches: a comparison of symptom-based and reported physician diagnosis. Arch Intern Med 1992;156:1273-1278.

148. Lipton RB, Silberstein SD, Stewart WF. An update on the epidemiology of migraine. Headache 1994; 34:319-328.

149. Stewart WF, Lipton RB, Celentano DD. Prevalence 
of migraine headache in the United States. JAMA 1992;267:64-69.

150. Hu XH, Markson LE, Lipton RB, Stewart WF, Berger ML. Burden of migraine in the United States: disability and economic costs. Arch Intern Med 1999;159:813-818.

151. Osterhaus JT, Gutterman DL, Plachetka JR. Healthcare resource and low labour costs of migraine headaches in the US. Pharmacoeconomics 1992;2:2-11.

152. Edmeads J, Mackell JA. The economic impact of migraine: an analysis of direct and indirect costs. Headache 2002;42:501-509.

153. Gerth WC, Carides GW, Dasbach EJ, Visser WH, Santanello NC. The multinational impact of migraine symptoms on healthcare utilisation and work loss. Pharmacoeconomics 2001;19:197-206.

154. Mushet GR, Miller D, Clements B, Pait DG, Gutterman D. Impact of sumatriptan on workplace productivity, nonwork activities, and health-related quality of life among hospital employees with migraine. Headache 1996;36:137-143.

155. Cohen JA, Beall D, Beck A, et al. Sumatriptan treatment for migraine in a health maintenenace organization: economic, humanistic, and clinical outcomes. Clin Ther 1999;21:190-205.

156. Adelman JU, Sharfman M, Johnson R, et al. Impact of oral sumatriptan on workplace productivity, health-related quality of life, healthcare use, and patient satisfaction with medication in nurses with migraine. Am J Manag Care 1996;2:1407-1416.

157. Cohen JA, Beall DG, Miller DW, Beck A, Pait G, Clements BD. Subcutaneous sumatriptan for the treatment of migraine: humanistic, economic, and clinical consequences. Fam Med 1996;28:171-177.

158. Jhingran P, Cady RK, Rubino J, Miller D, Grice RB, Gutterman DL. Improvements in health-related quality of life with sumatriptan treatment for migraine. J Med Econ 1996;42:36-42.

159. Solomon GD, Nielsen K, Miller D. The effects of sumatriptan on migraine: health-related quality of life. Med Interface 1995;June:134-141.

160. Solomon GD, Skobieranda FG, Genzen JR. Quality of life assessment among migraine patients treated with sumatriptan. Headache 1995;35:449-454.
161. Santanello NC, Polis AB, Hartmaier SL, Kramer MS, Block GA, Silberstein SD. Improvement in migrainespecific quality of life in a clinical trial of rizatriptan. Cephalalgia 1997;17:867-872.

162. Cady RC, Ryan R, Jhingran P, O'Quinn S, Pait DG. Sumatriptan injection reduces productivity loss during a migraine attack. Arch Intern Med 1998;158: 1013-1018.

163. Litaker DG, Solomon GD, Genzen JR. Impact of sumatriptan on clinic utilization and costs of care in migraineurs. Headache 1996;36:538-541.

164. Greiner DL, Addy SN. Sumatriptan use in a large group-model health maintenance organization. Am J Health Syst Pharm 1996;53:633-638.

165. Caro JJ, Getsios D. Pharmacoeconomic evidence and considerations for triptan treatment of migraine. Expert Opin Pharmacother 2002;3:237-248.

166. Lofland JH, Johnson NE, Batenhorst AS, Nash DB. Changes in resource use and outcomes for patients with migraine treated with sumatriptan: a managed care perspective. Arch Intern Med 1999;159: 857-863.

167. Lofland JH, Kim SS, Batenhorst AS, et al. Cost-effectiveness and cost-benefit of sumatriptan in patients with migraine. Mayo Clin Proc 2001;76:10931101.

168. Biddle AK, Shih YC, Kwong WJ. Cost-benefit analysis of sumatriptan tablets versus usual therapy for treatment of migraine. Pharmacotherapy 2000;20: 1356-1364.

169. Caro JJ, Getsios D, Raggio G, Caro G, Black L. Treatment of migraine in Canada with naratriptan: a costeffectiveness analysis. Headache 2001;41:456-464.

Address reprint requests to: Neil I. Goldfarb, B.A. Department of Health Policy Jefferson Medical College 1015 Walnut Street, Suite 115 Philadelphia, PA 19107

E-mail: neil.goldfarb@jefferson.edu 